\title{
Empirical Studies Use The Balanced Scorecard To Measure Government Performance
}

\author{
Muchriana Muchran \\ Universitas Muhammadiyah Makassar \\ Gagaring Pagalung \\ Universitas Hasanuddin
}

\begin{abstract}
This paper aims to identify and measure performance in the public sector using the Balanced Sorecard. The difference between the private sector and the public sector makes the implementation of the balanced scorecard in the public sector attractive to be reviewed further. The existence of the Public Sector Organization becomes quite important for the community because in its characteristics it is open to the public / community. The government is asked to be more responsive to the demands of its people, better improve the performance of the bureaucracy and its administration so that the quality of service to the community and those with an interest improves significantly, better in producing quality decisions, more aware of the fundamental changes that must be made to be able to compete with other countries and can carry out their duties in serving the community efficiently, effectively, transparently and accountably. In this study the author uses a literature study approach based on empirical studies or studies in several international journals relating to government performance measurement. The review of this article can be concluded that overall, the implementation of the Balanced Score Card in some public sector organizations can be used as a measure of financial and non-financial performance. This application is very useful to see how the organization is performing, so that when it is found that one perspective has no influence on financial performance, it can be a consideration in making decisions in managing the organization.
\end{abstract}

Keyword: Balanced Scorecard, Government Performance

\section{INTRODUCTION}

The existence of the Public Sector Organization becomes quite important for the community because in its characteristics it is open to the public / community. The government often has problems in providing convoluted and difficult services, to the point of being briefly criticized by the public. Critical becomes very necessary, because the budgeting used is part of the community's money (taxes, retributions, etc.) that the government processes for development. Therefore, the government is asked to be more responsive to the demands of its people, better improve the performance of the bureaucracy and its administration so that the quality of service to the community and those with an interest improves significantly, better in producing quality decisions, more aware of the fundamental changes that must be made to be able to compete with other countries and be able to carry out their duties in serving the community efficiently, effectively, transparently and accountably.

The government must be able to carry out its government so as to create good governance. Systematic evaluation, monitoring, and performance measurement to measure the progress achieved by local governments in a certain period of time also needs to be implemented. Government performance can be seen from two perspectives, namely financial performance and non-financial performance. 
To measure government performance, both financial and non-financial performance can use Balance Scorecard. But the different nature of the public sector makes BSC implementation interesting to learn. Therefore, this paper will discuss about observing BSC implementation in the public sector. Therefore, the purpose of this paper is to observe the implementation of BSC in the public sector.

\section{Government Performance}

\section{BASED THEORY}

Performance is a result of work that can be achieved by a person or group of people in an organization, in accordance with the responsibilities and responsibilities of each person in order to achieve the goals of the organization in a legal manner, not violating the law and in accordance with morals and ethics (Mahmudi 2010).

According to Mardiasmo (2009), the system of measuring public sector performance is a system that aims to help public managers assess the achievement of a strategy through financial and non-financial measures. Furthermore, according to Mardiasmo that the measurement of public sector performance is carried out to fulfill three purposes, namely: 1) Improving government performance, 2) Allocation of resources and decision making, 3) realizing public accountability and improving institutional communication.

\section{Performance Measurement Using a Balanced Scorecard}

According to Kaplan and Norton (1996), the Balanced Scorecard consists of 2 words, namely Balanced and Scorecard. Balanced means showing that the performance of personnel or employees is measured in a balanced manner and viewed from two aspects, namely financial and non-financial, short-term and long-term and in terms of internal and external. While the Scorecard is a card that is used to record the score of a person's performance results that will be used to compare with the results of actual performance.

Performance measurement is an important thing for an organization, including can be used to assess the success of a company and can also be used as a basis for developing a reward system in an organization. Performance measurement using the Balanced Scorecard has a broad scope, because it does not only consider financial aspects but also non-financial aspects. Performance measurement with the Balanced Scorecard is an alternative performance measurement based on four main things, namely finance, customers, internal business processes, learning and growth. The advantage of using the Balanced Scorecard is that the Balanced Scorecard approach strives to translate the company's mission and strategy into goals and measurements that are viewed from four perspectives: finance, customers, internal business processes, learning and growth.

\section{Perspectives in the Balanced Scorecard}

The Balanced Scorecard shows a performance measurement method that combines financial and non-financial measures (Kaplan and Norton, 1996). There are four perspectives on business performance measured in the Balanced Scorecard, namely: Financial Perspective, Customer Perspective, Internal Process Perspective, Learning and Growth Perspective.

\section{Balanced Scorecard Excellence}

\section{Balance Scorecard has several advantages}

\section{a. Comprehensive}

Balance Scorecard emphasizes performance measurement not only quantitative aspects, but also qualitative aspects. These four perspectives provide a balance between external measurements such as profit, while on internal measures such as new product development. 


\section{b. Coherent}

Balance Scorecard requires personnel to determine a causal relationship between the various objectives produced in each plan. Each target set in the financial perspective must have a causal relationship with financial goals both directly and indirectly.

\section{c. Balanced}

The balance of objectives produced by the planning system is important to produce long-term financial performance.

\section{d. Measured}

The size of the target produced by the planning system promises to achieve various targets produced by the system.

The Scorecard measures goals that are difficult to measure. Goals on the customer perspective, internal business processes, and learning and growth are targets that are not easy to measure, but in the third Balance Scorecard the third non-financial perspective can be measured.

\section{RESEARCH METHODS AND DATA COLLECTION}

This research is an empirical study by collecting several studies, then drawing conclusions from the study.

\section{DISCUSSION}

Khadijah (2002) in his research entitled Hospital Performance Evaluation X Period 1998-2001 Using Modified Balanced Scorecard, conducted a study aimed at knowing the description of the performance of RS X through the Balanced Scorecard approach, in terms of financial and nonfinancial. Descriptive research design and results of financial performance research , customer performance, internal business performance and growth and learning performance at the $\mathrm{X}$ hospital are not good.

Puspita (2003) with a research entitled Performance Assessment of Specialist Outpatient Unit at Palembang Regional General Hospital Bari Period 2001-2002 with the Balanced Scorecard concept approach. The purpose of this study is to conduct a comprehensive performance assessment through the Balanced Scorecard concept approach. Descriptive research design and research results show financial performance, customer performance, internal business performance, growth performance and learning is not good.

Hestiningsih (2004) conducted a study entitled The Performance Analysis of Inpatient Agencies of Pasar Rebo Regional General Hospital in Jakarta using the Balanced Scorecard Concept Approach. Descriptive research methods and from the four perspectives, showing a financial perspective are things that can be used in measuring performance, for 3 other perspectives it is difficult to use.

Irawani (2007) in his research entitled Performance Analysis with the Balanced Scorecard Approach at Martha Friska Hospital in Medan. The purpose of this study was to determine and analyze the performance of Medan Martha Friska Hospital in 2004-2006 with the Balanced Scorecard approach. This type of research is descriptive qualitative in the form of case studies and supported by surveys. The results show that in general the total score of the four perspectives has a pretty good value which means that the hospital has made progress in the measurement approach but still needs improvement in some perspectives that have low value. This means that balanced score cards can be used to measure performance. 
Pramadhany (2011) conducted a study entitled Application of the Balanced Scorecard Method as a Benchmark for Performance Assessment in Nonprofit Organizations. The research objective was to determine the performance of Bhayangkara Semarang Hospital based on the Balanced Scorecard performance assessment. Descriptive research methods and research results show the average value for each perspective, namely finance, customers, internal business, and learning and growth are quite good.

Hartati (2014) conducted a study entitled Dr. RSUD's Performance Assessment. Become a Field Using the Balanced Scorecard Approach. The purpose of the study was to determine and analyze the performance of Dr. Pirngadi Medan for the period 2010-2013 with the Balanced Scorecard approach. The research method is qualitative descriptive in the form of case studies and supported by surveys. The results of the hospital performance evaluation showed that overall the performance of Dr Pirngadi Medan Hospital seen from the four perspectives of balanced scorecard was quite good. Management needs to pay special attention to the measurement of indicators that are not good or good enough and maintain an assessment of good indicators in order to improve the performance of hospitals in the future.

NISTOR (2016), BSC's effectiveness in both the public and private sectors is given by its use in three important dimensions: performance measurement, strategy management and as an instrument of communication, which involves all interested parties in quality awareness and new culture. strategy. Nistor finds that perspectives for the public sector are different, stakeholder perspectives are first,

while the financial perspective is placed second. Furthermore, in this context, we created an index (LGA) based on the MDA framework combined with the BSC structure, which aims to assess the quality of information disclosed by the local government on their website. In the Romanian context, Law No. 544/2001 considers free access to public interest information and lists information that must be disclosed by public institutions either by posting on their website or in public places. An annual report is one item that must be disclosed voluntarily in accordance with this law. However, in Romania, most local governments failed to meet this requirement. The results of our investigation highlight that the local government in our sample shows severe deficiencies not only related to the quantity of information disclosed, but also about the complexity and completeness of the information if it is publicly available. The average disclosure rate is 47.42 with no local government capable of achieving the maximum score (85 points).

Thus, Nistor shows that the implementation of the BSC manages to improve the quality and performance management in the public sector through positive growth margins, especially considering that the development of the LGA Index is exclusively based on financial and nonfinancial items specifically for public spaces (see Appendix 1). In addition, our results are consistent with those achieved by similar studies examining the effectiveness of the BSC dimension in improving the performance of e-government service delivery (Lawson-Body, et al., 2008).

Hernández (2010). performance of public sector organizations, especially in terms of compliance with regulatory laws and budget constraints. However, the emphasis on financial measures tends to overshadow other relevant aspects to improve efficiency and effectiveness, looking for excellent public sector organizations. The BSC approach can help to achieve this aim and represent a step towards strategic planning and budgeting in the sphere sector community. Hernández gathered experience in implementing BSC in city sports services. In the process of designing a strategy map, we identified a lack of clear sports policy and strategic planning of its activities, wrong communication tools, the existence of competition in the 
provision of sports services, overlapping sports programs and the absence of a clear normative scheme to regulate competition in the provision of sports services as major weaknesses and threats to MAS's organization. However, MAS has a promising prospect for the future because its managers are motivated, staff are qualified and the organization offers consolidated sports activities and use of sports facilities.Based on these comments, the organization has established high-quality promotionssports services, universalization of sports and the creation of sports culture in IndonesiaGranada's population as its main strategic destination. To achieve this strategic goal, strategic objectives have been defined in each perspective, with special emphasis on customers and financial perspectives. Internal processes and learning and growth perspectives are focused on improving the quality of sports services; this perspective shows the importance of improving the results of administrative, technical and economic management. In particular, an increase in investment in enhancing sustainable employee training and training facilities is a strategic goal that is important in achieving the overall strategic goals of the organization. Once the strategic objectives have been established, performance drivers to meet them are agreed with the MAS manager. They are defined by a set of performance that matches the indicator. Thus, a causal relationship is used to achieve the strategic objectives of MAS, linking performance drivers with the BSC perspective to achieve the organization's strategic goals.

Pasaribua, M (2016) revealed that $40 \%$ of 15 public sector organizations that were reviewed still used the financial perspective as the highest result. This is because most of these organizations consider financial effectiveness to be the highest goal. In the future, it would be better to convert the highest results to customer / stakeholder satisfaction that is more oriented and put a financial perspective as support to achieve this goal. The other $40 \%$ of the reviewed papers have used the customer's perspective as the highest yield, while the remaining $20 \%$ use another perspective. The learning and growth perspective is considered to be the most important perspective because of low employee performance in the public sector. Therefore, many public sector organizations use this perspective to increase employee competency levels.

\section{CONCLUSION}

Overall, the implementation of the Balanced Score Card in some public sector organizations can be used as a measure of financial and non-financial performance. This application is very useful to see how the organization is performing, so that when it is found that one perspective has no influence on financial performance, it can be a consideration in making decisions in managing the organization.

\section{Reference}

Hestiningsih (2004) conducted a study entitled The Performance Analysis of Inpatient Agencies of Pasar Rebo Regional General Hospital in Jakarta using the Balanced Scorecard Concept Approach.

Hartati (2014) conducted a study entitled Dr. RSUD's Performance Assessment. Become a Field Using the Balanced Scorecard Approach.

Irawani (2007) in his research entitled Performance Analysis with the Balanced Scorecard Approach at Martha Friska Hospital in Medan

Khadija (2002). Performance Evaluation of Hospital Period 1998-2001 Using Modified Balanced Scorecard.

Puspita (2003) Performance Evaluation of Specialist Outpatient Unit of Palembang Regional General Hospital with Balanced Scorecard concept approach

Pramadhany (2011) conducted a study entitled Application of the Balanced Scorecard Method as a Benchmark for Performance Assessment on Nonprofit Organizations 
Kaplan R, Klein N (1996). Chemical bank: Implementing the Balanced Scorecard, Case Studies from Harvard Business School: Implementing the Balanced Scorecard. Harvard Business School Publishing;

Janota Rui and Maria João Major. 2012. The Balanced Scorecard in a Pharmaceutical Company: A Case Study. Maria Major's associate professor, Lisbon University Institute (ISCTE-IUL) and BRU / UNIDE researcher, Cacifo 105-A, Avenida das Forças Armadas, 1649-026 Lisbon, Portugal, Europe. Phone number: +351/217903495

NISTOR Cristina Silvia, Cristina Alexandrina ŞTEFĂNESCU, Mara Andreea SINTEJUDEANU. 2016. Performance management and Balanced Scorecard - a link for public sector. 6, n o. 3

Hernández Antonio M. López et al. 2010. Implementing the balanced scorecard in public sector agencies: An experience in municipal sport services * Implement the edition of del balanced scorecard en las agencias públicas: una experiencia en los servicios municipals deportivos. Academia, Revista Latinoamericana de Administración, 45, 2010, 116-139.

Pasaribua Amanah, M. Gilang Dwi Andikab, Reza Rachmandac, Dermawan (2016). A REVIEW OF MANAGEMENT PERFORMANCE USING THE BALANCED SCORECARD IN PUBLIC SECTOR. Bandung Institute of Technology,

Bandung, Indonesia 